\section{ITC 2/46}

Journal of Information Technology and Control

Vol. 46 / No.2/2017

pp. 228-234

DOI 10.5755/j01.itc.46.2.16208

(C) Kaunas University of Technology
A Note on the Use of Step Responses Matrix and Lambert W Function in the Dynamics Analysis of Time Delay Systems

Received 2016/09/07

Accepted after revision 2017/06/06

\title{
A Note on the Use of Step Responses Matrix and Lambert W Function in the Dynamics Analysis of Time Delay Systems
}

\section{Irma Jankauskienè, Jonas Rimas}

Kaunas University of Technology, Department of Applied Mathematics, Studentų st. 50, LT-51368, Kaunas, Lithuania; e-mails:irma.ivanoviene@yahoo.com,jonas.rimas@ktu.lt

Corresponding author: irma.ivanoviene@yahoo.com

For investigation of the dynamics of linear time-delay system, we propose to use the step responses matrix of the system and apply the Lambert $\mathrm{W}$ function method. The elements of this matrix in the first stage are being found on the interval $[0, \tau]$ (here $\tau$ is a fixed delay). For this, it is sufficient to solve an ordinary matrix differential equation. After that, using obtained solution as initial vector-function, elements of the step responses matrix are being found on the interval $(\tau,+\infty)$ by solving a linear homogeneous matrix delay differential equation. The well known Lambert W function method can be used for solution of this equation. The proposed method is illustrated on concrete time-delay systems.

KEYWORDS: differential equations, delayed arguments, Lambert W function.

\section{Introduction}

Using mathematical models that more exactly describe the behavior of the control system it is necessary to consider delays of the signal, transferred along the system. Such systems (with delays) are called time delay systems (TDS) [14]. In this article, we examine TDS, described by linear delay differential equations (DDEs) (differential equations with delayed argument). Due to delays TDS are infinite dimensional and for this reason their investigation is rather complicated. A comprehensive review of the results of investigation of TDS can be found in [19]. Several methods have been proposed to investigate stability and control problems of 
TDS, to find the absolute stability regions and investigate their dependence on delays $[15,20]$. Methods have been proposed to optimize the dominant root of the characteristic equation of TDS to guarantee a certain performance of the system [13]. The delay independent and delay dependent stabilities were considered in $[3,7,9,21,25]$. The delay independent stability of TDS (that is the stability maintained for all positive delays) was examined, and necessary and sufficient conditions for such stability can be found in [3, 7, 21]. The delay dependent stability of TDS (which corresponds to the case where TDS is stable for only a certain range of delay values) was investigated in [9, 25]. Recently a method for solution of linear DDEs, using Lambert W function was developed [14]. Some special cases in the stability analysis of multidimensional TDS, using the matrix Lambert $\mathrm{W}$ function, were dealt in $[2,4]$.

\section{Formulation of the problem}

Let us consider time-delay system described by a linear inhomogeneous system of delay differential equations presented in a matrix-vector form [1]:

$$
\begin{aligned}
& x^{\prime}(t)+A x(t)+B x(t-\tau)=z(t), \\
& x(t)=\phi(t), \quad t \in[-\tau, 0] ;
\end{aligned}
$$

here $x(t)=\left(\begin{array}{lll}x_{1}(t) & \ldots & x_{n}(t)\end{array}\right)^{T}$ is the vector function, $T$ here and further in the text denotes the operation of transposition, $\tau$ is a constant time-delay, $\phi(t)$ is an initial vector-function, $z(t)$ is a term depending on the initial conditions, $A$ and $B$ are $n \times n(n \in N)$ numerical matrices $\left(A, B \in R^{n \times n}\right)$.

One can obtain important information about transients in system by analysing reactions of the system to special types of impacts. Below, we shall use the unit leep as such an impact and apply Lambert W function method in the dynamics analysis of the TDS.

Next we present brief information on the Lambert W function (for detailed information about this function see, for example, [6]).

\section{Lambert W function}

The Lambert W function $W(z)$ is defined as the solution of a transcendental equation

$$
W(z) e^{W(z)}=z
$$

The function is broadly used in theoretical and applied sciences [5, 8, 10, 23, 24].

The Lambert $\mathrm{W}$ function, with a complex argument $z$, is a complex multi-valued function; that is, for any $z \in C$ there are infinite number of solutions to (2). We denote by $W_{k}(z)$ the $k$-th branch of the Lambert W function of $z(k=0, \pm 1, \pm 2, \ldots)$.

The comprehensive explanation of the branch cuts and the ranges of separate branches is given in [6].

Only two of the branches of Lambert $\mathrm{W}$ function have real values: $W_{0}(x)$ and $W_{-1}(x)$. As can be seen in Fig. 1, the branch $W_{-1}(x)$ is defined in the interval $\left[-e^{-1}, 0\right)$ and has a negative singularity for $x \rightarrow 0^{-}$. The branch $W_{0}(x)$ is defined in the interval $\left[-e^{-1},+\infty\right)$. The range of the branch $W_{0}(x)$ is the interval $[-1,+\infty)$ and that of the branch $W_{-1}(x)$ is the interval $(-\infty,-1]$.

If $z=H$ is a square matrix in (2), then the solution of (2) is a matrix Lambert W function $W(H)$.

\section{Figure 1}

The two real branches of Lambert $\mathrm{W}$ function $: W_{0}(x)(\ldots .$. and $W_{-1}(x)(-----)$.

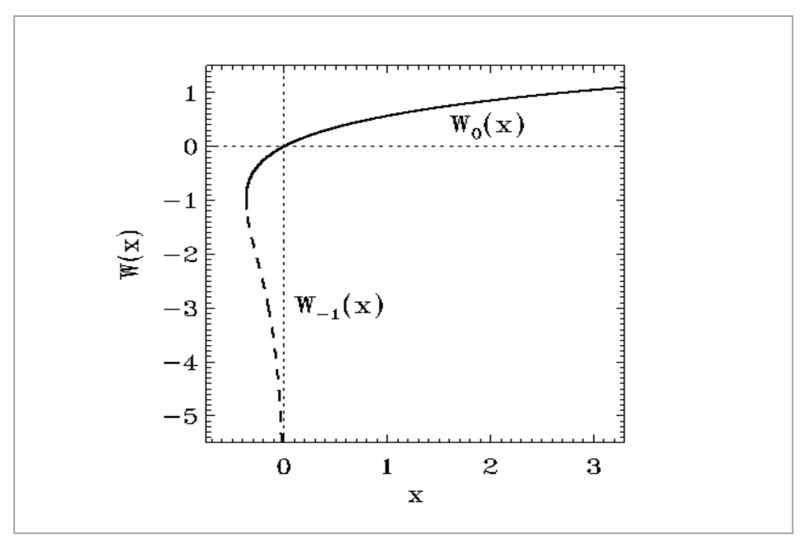

\section{Step responses matrix of the system}

Let delay system be described by (1) and $x(t)=$ $\left(\begin{array}{lll}x_{1}(t) \quad \ldots \quad x_{n}(t)\end{array}\right)^{T}$ be a solution of (1). The matrix $h(t)=$ $\left(h_{i j}(t)\right)$ we shall call the step responses matrix of the system if $h_{i j}(t)(i, j=\overline{1, n})$ is a response of $x_{i}(t)$ to a unit leap in $x_{j}(t)$ [16]. It should be emphasized that the step 
responses matrix gives the possibility to investigate reaction of the system to various interferencies. We shall determine the elements of $h(t)$.

When the change of the $j$-th component of the vector $x(t)$ takes form of the unit leap, the change of the free term of the equation (1) has the folowing form:

$$
\Delta z(t)=\delta(t) I^{(j)},
$$

here $I^{(j)}$ is the matrix-column all elements of which are zeros except the $j$-th element, which is equal to 1 , $\delta(t)$ is the Dirac delta-function. Differential equation for step responses $h_{i j}(t)=\left\{h_{j}(t)\right\}_{i}(i, j=\overline{1, n})$ of the system (1) has the form:

$$
\begin{aligned}
& h_{j}^{\prime}(t)+A h_{j}(t)+B h_{j}(t-\tau)=\delta(t) I^{(j)}, \quad j=1, n, \\
& h_{j}(t)=0, \quad t \in[-\tau, 0],
\end{aligned}
$$

here $h_{j}(t)=\left(h_{1 j}(t) \quad h_{2 j}(t) \quad \cdots \quad h_{j}(t)\right)^{T}$ is the $j$-th column of $h(t)$.

The components of $h_{j}(t-\tau)$ on the interval $[0, \tau]$ are zeros, consequently expression (4) on this interval can be presented as follows:

$$
\begin{aligned}
& h_{j}^{\prime}(t)+A h_{j}(t)=\delta(t) I^{(j)}, \quad j=\overline{1, n}, \\
& h_{j}(t)=0, \quad t \in[-\tau, 0] .
\end{aligned}
$$

The solution of (5) is a vector-function [22]:

$$
h_{j}(t)=e^{A t} I^{(j)} 1(t), \quad j=\overline{1, n}, t \in[0, \tau],
$$

here $1(t)$ is the Heaviside step function. The components of the vector-function $h_{j}(t)$ are:

$$
\begin{aligned}
& h_{i j}(t)=\left\{h_{j}(t)\right\}_{i}=\left\{e^{A t} I^{(j)}\right\}_{i} 1(t)= \\
& =\left\{e^{A t}\right\}_{i j} 1(t), i, j=\overline{1, n}, t \in[0, \tau] .
\end{aligned}
$$

The differential equation (4) on the interval $[\tau,+\infty)$ will be a linear homogeneous matrix delay differential equation:

$$
\begin{gathered}
h_{j}^{\prime}(t)+A h_{j}(t)+B h_{j}(t-\tau)=0, \\
j=\overline{1, n}, t>\tau, \\
h_{j}(t)=\varphi_{j}(t)=e^{A t} I^{(j)} 1(t), \quad t \in[0, \tau],
\end{gathered}
$$

here $\varphi_{j}(t)$ is the initial vector-function. The components of the vector-function $\varphi_{j}(t)$ will have values $(\operatorname{see}(7))$ :

$$
\varphi_{i j}(t)=\left(\varphi_{j}(t)\right)_{i}=\left\{e^{A t}\right\}_{i j} 1(t), i, j=\overline{1, n} .
$$

Let the matrices $A$ and $B$ in (8) commute. In that case, the solution of (8) on the interval $[\tau,+\infty)$, got applying the Lambert function method, will be (see, for example, [14]):

$$
\begin{aligned}
& h_{j}(t)=\sum_{k=-\infty}^{\infty} e^{S_{k} t} C_{k}(j)= \\
& =\lim _{N \rightarrow \infty} \sum_{k=-N}^{N} e^{S_{k^{t}}} C_{k}(j), j=\overline{1, n}, \quad t \in(\tau,+\infty),
\end{aligned}
$$

here

$$
S_{k}=\frac{1}{\tau} W_{k}\left(-B \tau e^{A \tau}\right)-A,
$$

$W_{k}\left(-B \tau e^{A \tau}\right)$ is the significance of the $k$-th branch $W_{k}(H)$ of the matrix Lambert function $W(H)$ at $H=-B \tau e^{A \tau}, C_{k}(j)$ are the complex valued vectors corresponding to the initial vector function $\varphi_{j}(t)$ (see (8) and (9)). The instructions for computing $C_{k}(j)$ and $W_{k}(H)$ can be found in [14]. From (10), the approximate expression for $h_{j}(t)$ on the interval $[\tau,+\infty)$ follows:

$$
h_{j}(t)=\sum_{k=-N}^{N} e^{S_{k} t} C_{k}(j), \quad j=\overline{1, n}
$$

here $N$ is a sufficiently big natural number.

Remark 1. Let the matrix $H$ in $S_{k}=\frac{1}{\tau} W_{k}(H)-A$ $\left(H=-B \tau e^{A \tau}\right), k \in Z$, have $s$ eigenvalues $\lambda_{1}, \ldots, \lambda_{s}$ with multiplicities $n_{1}, \ldots, n_{s}$, respectively. Then the Jordan form of the matrix $H$ will be (see [11, 12]):

$$
J=\operatorname{diag}\left(J_{n_{1}}\left(\lambda_{1}\right), \ldots, J_{n_{s}}\left(\lambda_{s}\right)\right) ;
$$

here $J_{n}(\lambda)$ is the $n \times n$ Jordan block corresponding to eigenvalue $\lambda$. By similarity transformation we have $H=T J T^{-1}$ and the Lambert $\mathrm{W}$ function of the matrix $H$ can be defined as follows:

$$
\begin{aligned}
& W_{k}(H)=T W_{k}(J) T^{-1}, \\
& W_{k}(J)=\operatorname{diag}\left(W_{k_{1}}\left(J_{n_{1}}\left(\lambda_{1}\right)\right), \ldots, W_{k_{s}}\left(J_{n_{s}}\left(\lambda_{s}\right)\right)\right),
\end{aligned}
$$




$$
\begin{aligned}
& W_{k}\left(J_{n}(\lambda)\right)= \\
& =\left(\begin{array}{cccc}
W_{k}(\lambda) & W_{k}^{\prime}(\lambda) & \cdots & \frac{1}{(n-1) !} W_{k}^{(n-1)}(\lambda) \\
0 & W_{k}(\lambda) & \cdots & \frac{1}{(n-2) !} W_{k}^{(n-2)}(\lambda) \\
\vdots & \vdots & & \vdots \\
0 & 0 & \cdots & W_{k}(\lambda)
\end{array}\right) .
\end{aligned}
$$

Remark 2. Let the matrix $H=-B \tau e^{A \tau}$ have zero eigenvalue: $W_{k}\left(\lambda_{i}\right)=W_{k}(0)$. It is known that [6]:

$$
W_{k}(0)=-\infty \text { if } k \neq 0
$$

and

$$
W_{k}(0)=0 \text { if } k=0 .
$$

We change the values of $W_{k}(0)$ at $k \neq 0$ as follows:

$$
W_{k}(0)=0 \text { if } k \neq 0 \text {. }
$$

This replacement is made by using known property of the Lambert W function:

$$
\begin{aligned}
& W_{k}(z) e^{W_{k}(z)}=z: \\
& W_{k}(0) e^{W_{k}(0)}=\lim _{x \rightarrow-\infty} x e^{x}=\lim _{x \rightarrow-\infty} \frac{x}{e^{-x}}= \\
& =\lim _{x \rightarrow-\infty} \frac{x^{\prime}}{\left(e^{-x}\right)^{\prime}}=\lim _{x \rightarrow-\infty} \frac{1}{-e^{-x}}=-\lim _{x \rightarrow+\infty} \frac{1}{e^{x}}=-0,
\end{aligned}
$$

if we apply (13), and $W_{k}(0) e^{W_{k}(0)}=0 e^{0}=0$, if we use (15).

Our presumption: the replacement

$$
\left(W_{k}(0)=-\infty \text {, if } k \neq 0\right) \Rightarrow\left(W_{k}(0)=0 \text {, if } k \neq 0\right)
$$

does not affect all the set of eigenvalues (it may affect only the order of elements in this set). It must be proved that this presumption is correct in general case. For the special case, given in the second example of Section 4, it is confirmed.

\section{The illustrative examples}

\section{Example 1}

In the first example, we shall illustrate the proposed method of investigation of dynamics of linear delay systems on the mutual synchronization system of the communication network [16]. Let the synchronization system be composed of $n(n \in N)$ mutually synchronized identical oscillators joined into a ring and its mathematical model be the matrix delay differential equation (1), in which $A=\kappa E, \kappa$ is some coefficient, $E$ is the identity matrix, $B=-\frac{\kappa}{2} U$ (note that $A$ and $B$ in this example are commuting matrices),

$$
U=\left(\begin{array}{cccccc}
0 & 1 & & & & 1 \\
1 & 0 & 1 & & & \\
& 1 & 0 & 1 & & \\
& & \ddots & \ddots & \ddots & \\
& & & 1 & 0 & 1 \\
1 & & & & 1 & 0
\end{array}\right)
$$

The matrix $U$ defines the structure of the internal links of the system (unmarked elements in $U$ are equal to zero). In this case, the symbol $x_{i}(t)$ in (1) means the phase of oscillation of the $i$-th oscillator. We shall find the step responses matrix $h(t)=h_{i j}(t)$ of the synchronization system; here

$h_{i j}(t)(i, j=\overline{1, n})$ is the response of the $i$-th oscillator oscillation phase to a unit leap in the $j$-th oscillator oscillation phase.

From (7), we get the expression for $h_{i j}(t)$ on the inter$\operatorname{val}[0, \tau]$ :

$$
\begin{aligned}
& h_{i j}(t)=\left\{h_{j}(t)\right\}_{i}=\left\{e^{A t}\right\}_{i j} 1(t)= \\
& =\left\{e^{-\kappa E t}\right\}_{i j} 1(t)=e^{-\kappa t}\{E\}_{i j} 1(t)= \\
& =e^{-\kappa t}\left\{I^{(j)}\right\}_{i} 1(t)=\left\{\begin{array}{lc}
e^{-\kappa t} 1(t), i=j, \\
0, & i \neq j
\end{array}\right.
\end{aligned}
$$

(we have taken into account the fact that the matrix exponential $e^{a E}$ with identity matrix $E$ and $a \in R$ can be expressed as follows: $e^{a E}=e^{a} E$ [22]).

We obtain the expression of $h_{i j}(t)$ on the interval $(\tau,+\infty)$ by taking into account the relation $h_{i j}(t)=\left\{h_{j}(t)\right\}_{i}$ and solving matrix linear homogeneous delay differential equation (8) with initial function $\varphi_{j}(t)$. This function is equal to $h_{j}(t)$ in the interval $[0, \tau]$ (see (16)): $h_{j}(t)=\varphi_{j}(t)=e^{-\kappa t} I^{(j)} 1(t), j=\overline{1, n}, t \in[0, \tau]$. The solution of (8) is presented in (10). In the real calculations, we use the approximate formula (12) obtained from (10) with finite $N(2 N+1$ denotes the number of 
branches of the Lambert $\mathrm{W}$ function, which are used in the calculation of the solution).

The curves of step responses $h_{11}(t)$ and $h_{21}(t)$, calculated by (16) on the interval $[0, \tau]$ and by the approximate formula (12) on the interval $(\tau,+\infty)$, are presented in Figures 2 and 3 . The curves in these figures are obtained with $N=50$. The corresponding curves, got by the method of consequent integration (see [17]) and by dde23 program in MATLAB, are not presented in these figures, since these curves and the curves obtained by the approximate formula (12) with $N=50$ visually coincide.

\section{Figure 2}

Dependence of the step response $h_{11}(t)$ on a delay $\tau$

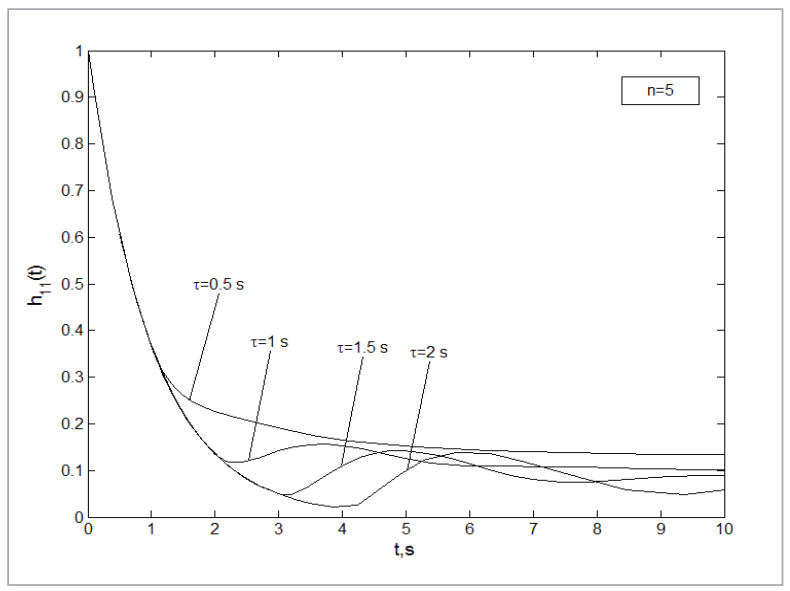

\section{Figure 3}

Dependence of the step response $h_{21}(t)$ on the number of oscillators in the system

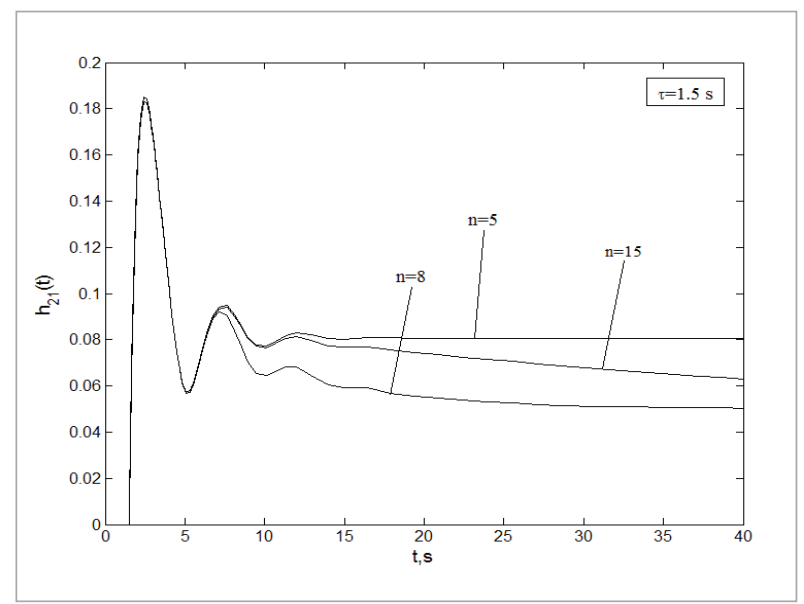

\section{Example 2}

The second example deals with forced synchronization system of the communication network [18].

Let the forced synchronization system be composed of $n(n \in N)$ identical oscillators joined into a chain and its mathematical model be the matrix delay differential equation (1), in which $A=\kappa E$, $\kappa$ is some coefficient, and $E$ is the identity matrix, $B=-\frac{\kappa}{2} U$,

$$
U=\left(\begin{array}{cccccc}
0 & 0 & & & & \\
1 & 0 & 1 & & & \\
& 1 & 0 & 1 & & \\
& & \ddots & \ddots & \ddots & \\
& & & 1 & 0 & 1 \\
& & & & 1 & 0
\end{array}\right)
$$

(matrix $U$ defines the structure of the internal links of the system; unmarked elements in $U$ are equal to zero). Note that $A$ and $B$ in this example, as well, are commuting matrices.

The symbol $x_{i}(t)$ in (1) means the phase of oscillation of the $i$-th oscillator. We shall find the step responses matrix $h(t)=h_{i j}(t)$ of the synchronization system.

From (7) we get the expression for $h_{i j}(t)$ on the interval $[0, \tau]$. It will be the same as in the first example (see (16)).

\section{Figure 4}

Curves of the step response $h_{22}(\kappa t)$ calculated by three methods: 1) the Lambert W function method with different values of $N, 2$ ) numerical method using dde23 program in MATLAB, 3) exact method of consequent integration (method of "steps")

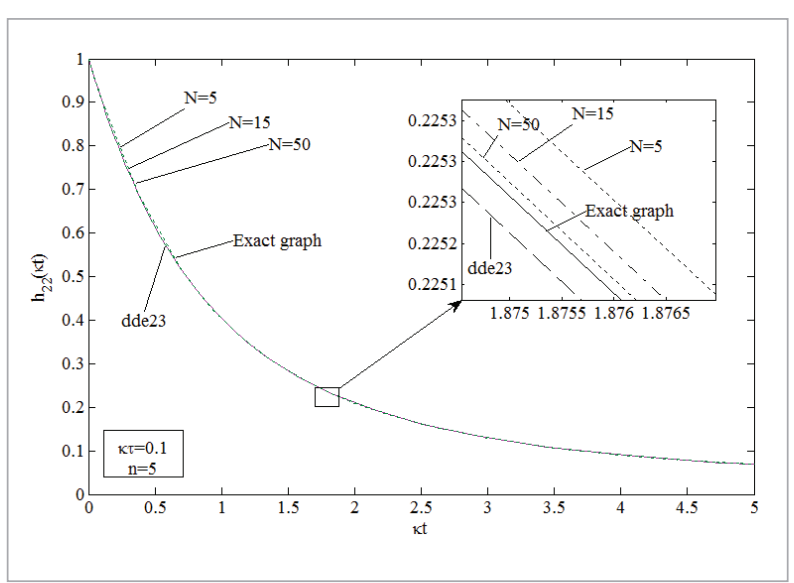




\section{Figure 5}

Curves of the step responses

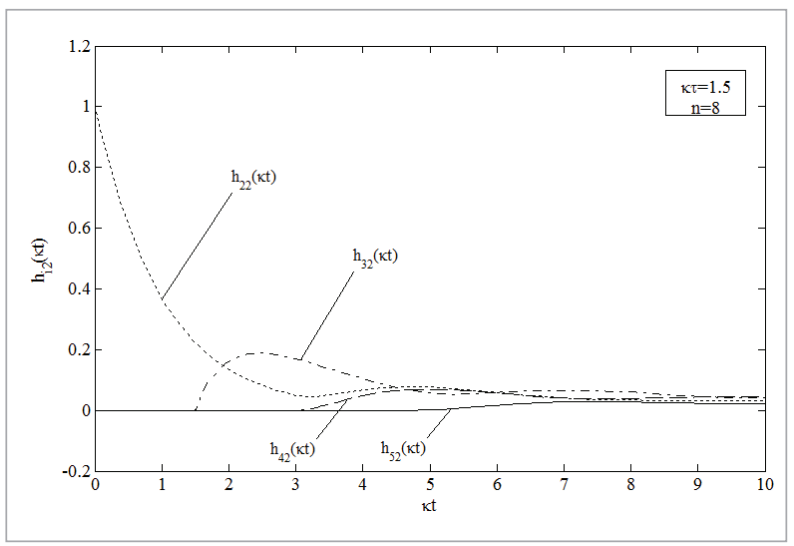

We obtain the expression of $h_{i j}(t)$ on the interval $(\tau,+\infty)$ by taking into account the relation $h_{i j}(t)=\left\{h_{j}(t)\right\}_{i}$ and solving matrix linear homogeneous delay differential equation (8) with initial function $\varphi_{j}(t)$. This function is equal to $h_{j}(t)$, found on the interval [0, $\left.\tau\right]$ (see (16)): $h_{j}(t)=\varphi_{j}(t)=e^{-k t} I^{(j)} 1(t), j=\overline{1, n}, t \in[0, \tau]$. The solution of (8) is presented in (10). In this case, the matrix $H=-B \tau e^{A \tau}$ in $S_{k}=\frac{1}{-} W_{k}(H)-A$ has zero eigenvalue, therefore, we perform the replacement according to Remark 2.

The curves of the step responses, calculated by (16) on the interval $[0, \tau]$ and by the approximate formula (12) on the interval $(\tau,+\infty)$, are presented in Figures 4 and 5. The curves in Figure 4 are obtained with different values of $N: N=5, N=15$ and $N=50$. The corresponding curves, obtained by the method of "steps" (see [18]) and by dde23 program, in Figure 4 are present-

\section{References}

1. Bellman, R., Cooke, K. L. Differential-difference equations. Academic Press, New York, 1963.

2. Cepeda-Gomez, R., Michiels, W. Some special cases in the stability analysis of multi-dimensional time delay systems using the matrix Lambert $\mathrm{W}$ function, Automatica, 2015, 53, 339-345. https://doi.org/10.1016/j.automatica.2015.01.016

3. Chen, J., Xu, D., Shafai, B. On sufficient conditions for stability independent of delay. IEEE Transactions on Automatic Control, 1995, 40, 1675-1680. https://doi. org/10.1109/9.412644

4. Choudhary, N., Sivaramakrishnan J., Narayan Kar I. Analysis of higher order time delay systems using Lambert W function. arXiv: 1604.01981v1 [cs.SY], 2016. ed as well. As we see from this figure, step responses, calculated by the Lambert $\mathrm{W}$ function method, approach the exact curves if the number of branches, used in calculations, is increasing. This result proves the supposition, which was made in Remark 2. The curves in Figure 5 are produced by taking $N=50$.

\section{Conclusions}

1 This article presents a method for the investigation of linear time-delay system, based on the application of step responses matrix of the system and on the use of the Lambert W function method for solution of linear homogeneous matrix delay differential equations. According to the proposed method, in the first stage, the elements of the step responses matrix are found on the interval $[0, \tau]$. For this, an ordinary matrix differential equation must be solved. Using the obtained solution as the initial vector function for the homogeneous delay differential equation, the elements of the step responses matrix, applying the Lambert W function method, are found on the interval $(\tau,+\infty)$.

2 If the matrix $H$ (the argument of the Lambert W function) has zero eigenvalue, it is proposed in this paper to change the value of the $k$-th branch $(k \neq 0)$ of the Lambert W function at zero argument to zero. This replacement, as it is shown in Example 2 , leads to good results.

3 The adduced examples show the applicability of the proposed method for investigation of the dynamics of linear delay systems.

5. Cogan, B., de Paor, A. M. Analytic root locus and Lambert $\mathrm{W}$ function in control of a process with time delay. Journal of Electrical Engineering, 2011, 62(6), 327-334. https://doi.org/10.2478/v10187-011-0052-9

6. Corless, R. M., Gonnet, G. H., D. Hare, E., Jeffrey, D. J., Knuth, D. E. On the Lambert W function. Advances in Computational Mathematics, 1996, 5, 329-359. https:// doi.org/10.1007/BF02124750

7. Delice, I. I., Sipahi, R. Delay independent stability test for systems with multiple time delays. IEEE Transactions on Automatic Control, 2012, 57, 963-972. https:// doi.org/10.1109/TAC.2011.2168992

8. Ding, J., Radhakrishnan, R. A new method to determine the optimum load of a real solar cell using the Lambert W 
function. Solar Energy Materials and Solar Cells, 2008, 92, 1566-1569. https://doi.org/10.1016/j.solmat.2008.07.004

9. Domoshnitsky, A., Fridman, E. A positivity-based approach to delay-dependent stability of systems with time-varying delays. Systems and Control Letters, 2016, 97, 139-148. https://doi.org/10.1016/j.sysconle.2016.09.011

10. Goličnik, M. On the Lambert W function and its utility in biochemical kinetics. Biochemical Engineering Journal, 2012, 63, 116-123. https://doi.org/10.1016/j. bej.2012.01.010

11. Higham, N. J. Functions of matrices: theory and computation. Society for Industrial and Applied Mathematics, Philadelphia, 2008. https://doi. org/10.1137/1.9780898717778

12. Horn, R., Johnson, C. Topics in Matrix Analysis. Cambridge University Press, UK, 1991. https://doi. org/10.1017/CBO9780511840371

13. Michiels, W., Engelborghs, K., Vansevenant, P., Roose, D. Continuous pole placement for delay equations. Automatica, 2002, 38(5), 747-761. https://doi.org/10.1016/ S0005-1098(01)00257-6

14. Yi, S., Nelson, P. W., Ulsoy, A. G. Time-delay systems (analysis and control using the Lambert W function). World Scientific, New Jersey, 2010. https://doi.org/10.1142/77759

15. Olgac, N., Sipahi, R. An exact method for the stability analysis of time-delayed linear time-invariant (LTI) systems. IEEE Transactions on Automatic Control, 2002, 47(5), 793-797. https://doi.org/10.1109/ TAC.2002.1000275

16. Rimas, J. Investigation of the Dynamics of Mutually Synchronized Systems. Telecommunications and Radio Engineering, 1977, 32, 68-79.
17. Rimas, J. Analysis of multidimensional delay system. In: MTNS 2004, Leuven, Belgium, 2004, 1-5.

18. Rimas, J. Analysis of a multidimensional control system with delays and chain form structure. In: ECT2008: The 3rd International Conference on Electrical and Control Technologies, May 8-9, Kaunas, Lithuania, 2008.

19. Sipahi, R., Niculescu, S. I., Abdallah, C., Michiels, W., $\mathrm{Gu}, \mathrm{K}$. Stability and stabilization of systems with time delay. IEEE Control Systems, 2011, 31(1), 38-65 https:// doi.org/10.1109/MCS.2010.939135

20. Sipahi, R., Olgac, N. A unique metodology for the stability robustness of multiple time delay systems. Systems and Control Letters, 2006, 55(10), 819-825. https://doi. org/10.1016/j.sysconle.2006.03.010

21. Souza, F. O., de Oliveira, M. C., Palhares, R. M. Stability independent of delay using rational functions. Automatica, 2009, 45, 2128-2133. https://doi.org/10.1016/j. automatica.2009.05.012

22. Teschl, G. Ordinary differential equations and dynamical systems. American Mathematical Society, Providence, 2012. https://doi.org/10.1090/gsm/140

23. Valluri, S. R., Gil, M., Jeffrey, D. J., Basu, S. The Lambert $\mathrm{W}$ function and quantum statistics. Journal of Mathematical Physics, 2009, 50, 1-11. https://doi. org/10.1063/1.3230482

24. Veberič, D. Lambert $W$ function for applications in physics. Computer Physics Communications, 2012, 183, 2622-2628. https://doi.org/10.1016/j.cpc.2012.07.008

25. Xu, Q., Stepan, G., Wang, Z. Delay-dependent stability analysis by using delay-independent integral evaluation. Automatica, 2016, 70, 153-15\%. https://doi. org/10.1016/j.automatica.2016.03.028

\section{Summary / Santrauka}

For investigation of the dynamics of linear time-delay system, we propose to use the step responses matrix of the system and apply the Lambert W function method. The elements of this matrix in the first stage are being found on the interval $[0, \tau]$ (here $\tau$ is a fixed delay). For this, it is sufficient to solve an ordinary matrix differential equation. After that, using obtained solution as initial vector-function, elements of the step responses matrix are being found on the interval $(\tau,+\infty)$ by solving a linear homogeneous matrix delay differential equation. The well known Lambert W function method can be used for solution of this equation. The proposed method is illustrated on concrete time-delay systems.

Straipsnyje tiriant tiesinių sistemų su vèlavimais dinamiką pasiūlyta naudoti sistemų pereinamųjų funkcijų matricas ir Lamberto W funkciją. Taikant šį metodą, pirmame etape randamos pereinamosios funkcijos vèlavimo ilgio intervale[0, $\tau$ ], sprendžiant paprastąją tiesinę matricinę diferencialinę lygtį. Toliau, tariant, kad surastas sprendinys yra pradine funkcija, sistemos pereinamosios funkcijos intervale $(\tau,+\infty)$ randamos sprendžiant tiesinę homogeninę matricinę diferencialinę lygtị su vẻluojančiu argumentu. Šiai lygčiai spręsti gali būti taikomas žinomas metodas, paremtas Lamberto W funkcijos taikymu. Pateikti pasiūlytą metodą iliustruojantys pavyzdžiai. 